\title{
Application of a New Cell Model for the Equation of State to 20 Polymer Melts and a Blend Melt
}

\author{
Masahiko MURAKAMI ${ }^{\dagger}$ \\ 14-3-506 Kawahigashi-cho, Fushimi-ku, Kyoto 612-8375, Japan
}

(Received December 14, 2004; Accepted February 22, 2005; Published May 15, 2005)

\begin{abstract}
In a previous publication, we reported a new cell model for the equation of state of polymer melts. The equation contains external degrees of freedom explicitly as a function of molecular weight of repeating unit. In this paper, we apply the theory to 20 polymer melts and a blend melt. The linear lengths of the coarse-grained particle (CGP) of several polymers coincide with those obtained by scattering experiments. In addition, we estimated the characteristic quantity $T^{*}$ of the equation of state per repeating unit using van der Waals constants and the critical temperature of the repeating unit or monomer. The values, $T^{*}$, agreed with those from our result per repeating unit. This result suggests the quantitative validity of our theory. We strongly suggest that our theory must be related to the conformer model by Matsuoka and the helical wormlike chain model by Yamakawa, because $T^{*}$ must be dependent on the chemical structure and stiffness of the polymers. [DOI 10.1295/polymj.37.363]

KEY WORDS Polymer Melt / Blend Melt / Equation of State / Coarse-grained Particle (CGP) / Characteristic Quantity $T^{*}$ of the Equation of State / New Cell Model / Degrees of Freedom /
\end{abstract}

Our new cell model for the equation of state $^{1}$ is based on the classical cell model by Lennard-Jones and Devonshire theory. ${ }^{2}$ A new definition of the integral limit ${ }^{1,3}$ for estimating the free volume of the cell results in the equation of state being similar to van der Waals equation of state. ${ }^{4}$ If we assume that the potential between coarse-grained particles (CGPs) is the only excluded volume in the free volume term, the equation coincides with van der Waals equation of state. ${ }^{4}$ Though van der Waals equation of state ${ }^{4}$ implicitly contains external degrees of freedom, our theory ${ }^{1}$ contains the external degrees of freedom explicitly as a function of molecular weight of repeating unit in the free volume term, because of the consideration of the potential between the CGPs using the Sutherland potential. As a result, van der Waals equation of state ${ }^{4}$ is the approximate theory of our theory. ${ }^{1}$ It should be noted that our theory ${ }^{1}$ is rigorous and the only theory in history which explicitly contains the external degrees of freedom and only our theory can quantitatively discuss the characteristic quantities per CGP or per repeating unit of the polymer. In addition, we suggest that by considering the temperature dependence of the core volume, our theory ${ }^{5}$ is very successful.

In this paper, we apply our theory to 20 polymer melts and a blend melt, and discuss the quantitative validity of our theory for application to any polymer or blend melt.

We estimate the coefficient of thermal expansion of the polymers using the same definition in our previous paper. ${ }^{1}$ We estimate the dimensions of the CGP, whose external degrees of freedom are equal to $c=1$, of 20 polymers and a blend using PVT data of these polymers and a blend. In addition, we estimated the characteristic quantity of the equation of state $T^{*}$ per repeating unit by using van der Waals constants and the critical temperature of the repeating unit or monomer.

\section{OUTLINE OF THE NEW CELL MODEL OF THE EQUATION OF STATE}

In a previous publication, ${ }^{1}$ we reported a new cell model for the equation of state. The theory is based on the classical cell model by Lennard-Jones and Devonshire. $^{2}$ We use the Sutherland potential instead of the Lennard-Jones potential. Because of the connectivity of successive segments in the polymer, the segments in a polymer are more compact between successive segments than those in simple liquids, while the distance between the intermolecular segments are similar to those in simple liquids. Combined with these two situations, the cell model can be applicable to polymer systems. In addition considering the temperature dependence of the core volume is one of the reasons for success of our theory.

Following Sanchez et al., ${ }^{3,6}$ we estimated the coordination number of the classical cell model being equal to $4 \pi / 3$.

Following Prigogine, ${ }^{7}$ the degrees of freedom of a molecule in liquids can be separated into internal and external ones. As reported in a previous paper, ${ }^{1}$ we introduce a CGP composed of $1 / c$ repeating units (where $c$ is the external degrees of freedom per repeat-

${ }^{\dagger}$ To whom correspondence should be addressed (E-mail: murakamim@ mub.bigloge.ne.jp). 
ing unit), the external degrees of freedom of the particle are equal to 1 ; and the particle is a disconnected, freely and translationally movable particle. Flory et $a l^{8}$ considered that the external degree of freedom depends only on the intermolecular interaction and corresponds to the translational motion in one direction. Since we use the definition of the integral limit $\rho_{\max }$ in a free volume, the equation is similar to van der Waals equation. The definition ${ }^{1,3}$ is $4 \pi \rho_{\max }{ }^{3} / 3=$ $v-b$, where $v$ and $b$ are the volume of the cell per CGP and the van der Waals constant per CGP, respectively. Also, the $b$ value has a temperature dependence. $^{1}$

It should be noted that by using the Sutherland potential, we have a correction term, $f(c, \tilde{V}, \tilde{T})$, which explicitly contain $c$, and the modified free volume in the van der Waals equation of state ${ }^{4}$ for the polymer liquids as follows:

$$
\begin{aligned}
V_{f} & =\sigma_{0}^{3} \tilde{V}_{f}=\sigma_{0}^{3}[\tilde{V}-(1+\tilde{\alpha} \tilde{T} / 2)]+\sigma_{0}^{3} f(c, \tilde{V}, \tilde{T}) \\
c & =P^{*} v^{*} /\left(k T^{*}\right)=P^{*} V_{0}^{*} M /\left(k T^{*} N_{\mathrm{A}}\right) .
\end{aligned}
$$

where $P^{*}, V_{0}^{*}$ and $T^{*}$ are the characteristic quantities in the equation of state defined at $0 \mathrm{~K},{ }^{9,10}$ and $\sigma_{0}$, $\tilde{V}=V / V_{0}^{*}, V, \tilde{\alpha}=\alpha T^{*}, \alpha, \tilde{T}=T / T^{*}, T, v^{*}, k, M$ and $N_{\mathrm{A}}$ are the linear length of the CGP at $0 \mathrm{~K}$, the reduced volume, the specific volume of the system, the reduced thermal expansion coefficient, the thermal expansion coefficient, reduced temperature, temperature, the core volume per CGP at $0 \mathrm{~K}$, Boltzman's constant, molecular weight per repeating unit and Avogadro's constant, respectively.

$c T^{*}$ is proportional to the depth of the Sutherland potential well per repeating unit. $c R T^{*}$ is defined as the heat of vaporization of a hypothetical liquid at $0 \mathrm{~K}$ per repeating unit. ${ }^{9}$

\section{THE THERMAL EXPANSION COEFFICIENTS}

In the previous paper ${ }^{1}$ we assumed that the specific volume of the CGP is the same as that of a single crystal, so we estimated the coefficient of thermal expansion, $\alpha$, using the lattice constants of a single crystal of polyethylene (PE), and estimated the dimension of the CGP of PE.

We estimated $\alpha$ for polymers using the following equation $^{11}$ that is the same definition as discussed in our previous paper. ${ }^{1}$

$$
\alpha=\left(V_{\mathrm{c}}^{*}-V_{0}^{*}\right) /\left(T V_{0}^{*}\right)=E_{\mathrm{c}} / V_{0}^{*} \simeq E_{\mathrm{g}} / V_{0}^{*}
$$

where $V_{\mathrm{c}}^{*}$ and $V_{0}^{*}$ are the molar volumes per repeating unit of crystal at 298 and $0 \mathrm{~K}$, respectively, and $T=298 \mathrm{~K} . E_{\mathrm{c}}$ and $E_{\mathrm{g}}$ are experimental data defined for the crystalline state and glassy state, respectively. According to Van Krevelen et al. ${ }^{11}$ we assume
$E_{\mathrm{c}} \simeq E_{\mathrm{g}}$, and we used the relation; $V_{0}^{*}=1.3 V_{\mathrm{w}}$ because we have no experimental data of $V_{0}^{*}$, where $V_{\mathrm{w}}$ is the van der Waals volume ${ }^{11}$ per mole which is calculated using the van der Waals radii. We used the experimental values ${ }^{11}$ of $E_{\mathrm{g}}$, but for poly(ethylene oxide) (PEO) we used calculated value ${ }^{11}$ of $E_{\mathrm{g}}$. Though Van Krevelen et al. ${ }^{11}$ showed two experimental data points of $E_{\mathrm{g}}$ for polystylene (PS), poly(ethylene terephthalate) (PET), poly(vinyl acetate) (PVAC), polyisobutylene (PIB) and poly(vinyl chloride) (PVC), we used the lower data because $E_{\mathrm{c}}$ must be smaller than $E_{\mathrm{g}}$. Since we have no data of $E_{\mathrm{g}}$ for poly(dimethyl siloxane) (PDMS), poly(vinyl methyl ether) (PVME) and poly(methacrylic acid) (PMA), we used the relation: ${ }^{11} V_{0}^{*}=1.3 V_{\mathrm{w}}$ and $V_{\mathrm{c}}^{*}=$ $1.435 V_{\mathrm{w}}$. In this case, $\alpha=3.5 \times 10^{-4} \mathrm{~K}^{-1}$. For PS/ PVME (50/50 blend), we estimated $\alpha$ and $M$ using the mole fraction. These results are shown in Table I.

\section{ESTIMATION OF $c T^{*}$}

Van der Waals constants $a$ and $b$ are related to the critical temperature $\left(T_{\mathrm{c}}\right)$ and critical volume $\left(V_{\mathrm{c}}\right)$.

$$
a=27 R T_{\mathrm{c}} b / 8 \quad b=V_{\mathrm{c}} / 3
$$

For gas, $a$ and $b$ per mole are derived by using the Sutherland potential, $(\phi(r))$, of a hard core with attractive tail, as follows

$$
\begin{aligned}
& a=-2 \pi N_{\mathrm{A}}^{2} \int_{0}^{\infty} \phi(r) r^{2} \mathrm{~d} r=\frac{2 \pi}{3} N_{\mathrm{A}}^{2} \sigma^{3} \varepsilon_{0} \\
& b=\frac{2 \pi}{3} N_{\mathrm{A}} \sigma^{3}
\end{aligned}
$$

where $\varepsilon_{0}\left(=4 \varepsilon_{\mathrm{LJ}}\right)$ is the depth of the potential well of the Sutherland potential and $\varepsilon_{\mathrm{LJ}}$ is that of LennardJones potential, and $\sigma$ is the diameter of the gas molecules.

$$
T^{*}=\frac{2 \pi}{3} \frac{\varepsilon_{0}}{k}=\frac{9 \pi}{4} T_{\mathrm{c}}
$$

We evaluated $T_{\mathrm{m}}^{*}$ and $T_{\mathrm{r}}^{*}$ ( $T^{*}$ per monomer and repeating unit, respectively) using eq 7 . We estimated $T_{\mathrm{LJ}}^{*}=$ $8 \pi \varepsilon_{\mathrm{LJ}} /(3 k)$ of ethylene and propylene using $\varepsilon_{\mathrm{LJ}} / k$. We use $T_{\mathrm{c}}$ of the monomer as the reference. ${ }^{12,13}$ We estimated $T_{\mathrm{c}}$ of the repeating unit using Fedors method. ${ }^{12}$ In Table III, we show $T_{\mathrm{m}}^{*}, T_{\mathrm{LJ}}^{*}, T_{\mathrm{r}}^{*}, c T^{*}$ (results of our theory per repeating unit) and $c T^{*} / M$.

\section{RESULTS AND DISCUSSION}

Utilizing a nonlinear least squares method, ${ }^{14}$ we fit the experimental $P V T$ data of 18 polymer melts and a blend melt, ${ }^{15}$ i-poly(methyl methacrylate) (iPMMA) ${ }^{16}$ and PVME $^{17}$ with the equation of state to get the values of $P^{*}, V_{0}^{*}$ and $T^{*}$ after some trial and 
Table I. The characteristic quantities of our equation of state for Polymers, dimension of coarse-grained particles, external degrees of freedom per repeating unit and $\alpha$

\begin{tabular}{lccccccc}
\hline $\begin{array}{c}\text { Data no. } \\
\text { 一 }\end{array}$ & $\begin{array}{c}S^{2} \\
\left(\mathrm{MPa}^{2}\right)\end{array}$ & $\begin{array}{c}P^{*} \\
(\mathrm{MPa})\end{array}$ & $\begin{array}{c}V_{0}^{*} \\
\left(10^{-3} \mathrm{~m}^{3} / \mathrm{kg}\right)\end{array}$ & $\begin{array}{c}T^{*} \\
(\mathrm{~K})\end{array}$ & $\begin{array}{c}\sigma_{0} \\
\left(10^{-10} \mathrm{~m}\right)\end{array}$ & $\begin{array}{c}c \\
-\end{array}$ & $\begin{array}{c}\alpha \\
\left(10^{-4} \mathrm{~K}^{-1}\right)\end{array}$ \\
\hline PE & 4.8 & 516.8 & 0.9398 & 2509 & 4.062 & 0.3265 & 2.073 \\
PEO & 5.0 & 720.0 & 0.5881 & 1472 & 3.045 & 1.524 & 3.5 \\
POM & 1.3 & 703.1 & 0.6026 & 2864 & 3.831 & 0.5343 & 3.0 \\
PET & 7.9 & 330.6 & 0.4169 & 358.8 & 2.465 & 8.878 & 3.5 \\
PMA & 11 & 648.5 & 0.4009 & 346.6 & 1.947 & 7.767 & 3.5 \\
PMAC & 7.5 & 530.5 & 0.5139 & 890.8 & 2.852 & 3.168 & 2.6 \\
PMMA & 12 & 520.4 & 0.5165 & 968.2 & 2.951 & 3.343 & 3.2 \\
PMMA** & 13 & 521.1 & 0.5220 & 1010 & 2.991 & 3.245 & 3.2 \\
i-PMMA & 30 & 550.3 & 0.5113 & 982.0 & 2.910 & 3.450 & 3.2 \\
a-PP & 1.6 & 318.3 & 0.9573 & 2775 & 4.937 & 0.5558 & 2.3 \\
i-PP & 4.1 & 379.9 & 0.9239 & 2614 & 4.563 & 0.6796 & 2.3 \\
PPMA & 13 & 353.5 & 0.7045 & 3500 & 5.151 & 1.097 & 4.1 \\
PS/PVME & 5.4 & 463.3 & 0.7390 & 3368 & 4.647 & 0.9118 & 3.0 \\
PVME & 2.8 & 457.2 & 0.7490 & 3057 & 4.519 & 0.7826 & 3.5 \\
PVAL & 15 & 1214 & 0.3886 & 296.6 & 1.500 & 8.430 & 4.1 \\
PVAC & 7.2 & 504.8 & 0.5296 & 905.3 & 2.915 & 3.057 & 2.6 \\
PVC & 13 & 802.3 & 0.4376 & 913.8 & 2.505 & 2.888 & 2.3 \\
PVF & 10 & 730.4 & 0.4064 & 1500 & 3.050 & 1.523 & 2.3 \\
\hline
\end{tabular}

PE (0-200 MPa, $199.7-240.6^{\circ} \mathrm{C}$, data 55 points); PEO (0-200 MPa, 159.1-198.7 ${ }^{\circ} \mathrm{C}$, data 55 points); POM (0196.1 MPa, 200.4-220.9 ${ }^{\circ} \mathrm{C}$, data 33 points); PET (0-200 MPa, 298.7-340.6 ${ }^{\circ} \mathrm{C}$, data 55 points); PMA (0-200 $\mathrm{MPa}, 252.2-277.0^{\circ} \mathrm{C}$, data 55 points); PMAC $\left(0-196.1 \mathrm{MPa}, 190.1-219.6^{\circ} \mathrm{C}\right.$, data 55 points); PMMA* $\left(M=10^{5}\right)$ (0-196.1 MPa, $190.4-230.4^{\circ} \mathrm{C}$, data 55 points); PMMA $^{* *}(M=10000)\left(0-200 \mathrm{MPa}, 190.9-230.8^{\circ} \mathrm{C}\right.$, data 55 points); i-PMMA (0.1-200 MPa, $116.3-190.2^{\circ} \mathrm{C}$, data 60 points); a-PP (0-200 MPa, 257.9-306.6 ${ }^{\circ} \mathrm{C}$, data 55 points); i-PP (0-196.13 MPa, 189.9-230.2 ${ }^{\circ} \mathrm{C}$, data 55 points); PPMA (0-196.1 MPa, 178.8-205.8 ${ }^{\circ}$, data 55 points); PS/ PVME (0-200 MPa, $165.1-198.5^{\circ} \mathrm{C}$, data 55 points); PVME (0-200 MPa, 150.0-190.0 ${ }^{\circ} \mathrm{C}$, data 55 points); PVAL (0-200 MPa, 228.9-237. ${ }^{\circ} \mathrm{C}$, data 44 points); PVAC (0-200 MPa, 170.5-203.6 ${ }^{\circ} \mathrm{C}$, data 55 points); PVC (0-196.1 $\mathrm{MPa}, 149.5-182.9^{\circ} \mathrm{C}$, data 55 points); $\mathrm{PVF}\left(0-200 \mathrm{MPa}, 199.5-230.9^{\circ} \mathrm{C}\right.$, data 44 points).

Table II. The characteristic quantities of our equation of state for PS, PDMS and PIB, dimension of coarse-grained particles, external degrees of freedom per repeating unit and $\alpha$

\begin{tabular}{lccccccc}
\hline $\begin{array}{c}\text { Data no. } \\
\text { 一 }\end{array}$ & $\begin{array}{c}S^{2} \\
\left(\mathrm{MPa}^{2}\right)\end{array}$ & $\begin{array}{c}P^{*} \\
(\mathrm{MPa})\end{array}$ & $\begin{array}{c}V_{0}^{*} \\
\left(10^{-3} \mathrm{~m}^{3} / \mathrm{kg}\right)\end{array}$ & $\begin{array}{c}T^{*} \\
(\mathrm{~K})\end{array}$ & $\begin{array}{c}\sigma_{0} \\
\left(10^{-10} \mathrm{~m}\right)\end{array}$ & $\begin{array}{c}c \\
-\end{array}$ & $\begin{array}{c}\alpha \\
\left(10^{-4} \mathrm{~K}^{-1}\right)\end{array}$ \\
\hline PS $^{*}$ & 5.3 & 451.4 & 0.7505 & 4238 & 5.061 & 1.001 & 2.2 \\
PS $^{* *}$ & 6.7 & 404.6 & 0.7608 & 4179 & 5.225 & 0.9226 & 2.2 \\
PDMS $^{*}$ & 2.5 & 250.9 & 0.7781 & 2170 & 4.925 & 0.8022 & 3.5 \\
PDMS $^{* *}$ & 2.0 & 228.1 & 0.7845 & 2107 & 5.034 & 0.7574 & 3.5 \\
PIB $^{*}$ & 11.4 & 404.0 & 0.9153 & 3887 & 5.103 & 0.6418 & 1.7 \\
PIB $^{* *}$ & 11.7 & 368.1 & 0.9195 & 3653 & 5.156 & 0.6251 & 1.7 \\
\hline
\end{tabular}

PS* (0-200 MPa, $179.8-209.7^{\circ} \mathrm{C}$, data 44 points); PS** (0-200 MPa, 219.4-251.3 ${ }^{\circ} \mathrm{C}$, data 44 points); PDMS* $\left(0-200 \mathrm{MPa}, 150.7-197.5^{\circ} \mathrm{C}\right.$, data 55 points); $\mathrm{PDMS}^{* *}\left(0-200 \mathrm{MPa}, 209.4-258.3^{\circ} \mathrm{C}\right.$, data 55 points); PIB* (0-200 MPa, $198.3-246.7^{\circ} \mathrm{C}$, data 55 points); $\mathrm{PIB}^{* *}$ (0-200 MPa, 258.7-305.6 ${ }^{\circ} \mathrm{C}$, data 55 points).

error. In Tables I and II, we show the final results of $S^{2}$ (the fitting goodness to $P$ ), $P^{*}, V_{0}^{*}, T^{*}, \sigma_{0}$ (linear length of CGP at $0 \mathrm{~K}$ ), $c$ and $\alpha$. Especially, in Table II, we examine the temperature dependence of the results.

$$
\sigma_{0}^{3}=v^{*} / c=V_{0}^{*} M /\left(c N_{\mathrm{A}}\right)=k T^{*} / P^{*}
$$

We insist that $\sigma_{0}, v^{*}\left(=V_{0}^{*} M / N_{\mathrm{A}}\right), c$ and $V_{0}^{*}$ in eq 8 should be defined ${ }^{10}$ at $0 \mathrm{~K}$.

In a previous paper, ${ }^{1}$ we reported that the linear length of the CGP of polyethylene at $443 \mathrm{~K}\left(\sigma_{\mathrm{c}}\right)$ agrees with the scattering experiments ${ }^{18}(4.34 \AA)$; at that time our average result is $\sigma_{\mathrm{c}}=4.21 \AA$. The new results are $\sigma_{\mathrm{c}}=5.22 \AA$ for PS and $\sigma_{\mathrm{c}}=2.95 \AA$ for PMMA $^{*}, \sigma_{\mathrm{c}}=3.02 \AA$ for PVAC and $\sigma_{\mathrm{c}}=1.58 \AA$ for poly(vinyl alcohol) (PVAL) at $443 \mathrm{~K}$, respectively. If we observe Figure 10a in reference ${ }^{19}$ to the total correlation function, we have peaks around 5, 10, $15 \AA$ for PS. Bjørnhaug et al. ${ }^{20}$ also reported a radial electric distribution function of several polymers in 
Table III. $T^{*}$ for monomer $\left(T_{\mathrm{m}}^{*}\right), T^{*}$ obtained by using Lennard-Jones parameter of monomer $\left(T_{\mathrm{LJ}}^{*}\right), T^{*}$ obtained by using $T_{\mathrm{c}}$ of repeating unit $\left(T_{\mathrm{r}}^{*}\right)$ and our result $c T^{*}$ and $c T^{*} / M$

\begin{tabular}{lccccc}
\hline \multicolumn{1}{c}{ Data no. } & $\begin{array}{c}T_{\mathrm{m}}^{*} \\
\text { - }\end{array}$ & $\begin{array}{c}T_{\mathrm{LJ}}^{*} \\
(\mathrm{~K})\end{array}$ & $\begin{array}{c}T_{\mathrm{r}}^{*} \\
(\mathrm{~K})\end{array}$ & $\begin{array}{c}c T^{*} \\
(\mathrm{~K})\end{array}$ & $\begin{array}{c}c T^{*} / M \\
(\mathrm{~K} / \mathrm{g})\end{array}$ \\
\hline PE & 998 & 941 & 810 & 808.8 & 57.7 \\
i-PP & 2578 & 2504 & 2095 & 1776 & 42.2 \\
a-PP & 2578 & - & 2095 & 1542 & 36.7 \\
PIB* $^{*}$ & $2954^{\mathrm{a}}$ & - & 2542 & 2495 & 44.5 \\
PS* $^{*}$ & 4578 & - & 4245 & 4244 & 40.8 \\
PVAC & 3711 & - & 3590 & 2768 & 32.2 \\
PVC & 3037 & - & 2940 & 2639 & 42.2 \\
PMMA & 3981 & - & 3785 & 3237 & 32.3 \\
PMMA** & 3981 & - & 3785 & 3276 & 32.7 \\
i-PMMA & 3981 & - & 3785 & 3388 & 33.8 \\
PMAC & 3789 & - & 3590 & 2823 & 32.8 \\
PVME & 3082 & - & 2689 & 2392 & 41.2 \\
PEO & - & - & 2372 & 2243 & 50.9 \\
POM & - & - & 1749 & 1530 & 51.0 \\
PET & - & - & 5273 & 3186 & 16.6 \\
PVAL & - & - & 3292 & 2500 & 56.8 \\
PMA & - & - & 4290 & 2692 & 31.3 \\
PPMA & - & - & 4174 & 3839 & 30.0 \\
PDMS* & - & - & - & 1741 & 23.5 \\
PVF & - & - & 2745 & 2286 & 35.7 \\
PS/PVME & - & - & - & 3071 & 41.2 \\
\hline
\end{tabular}

${ }^{\mathrm{a}}$ We use the datum $T_{\mathrm{c}}$ in ref 13 .

Figure 2 of their paper. The figure shows that PS has peaks around 5 and $10 \AA$, PMMA has peaks around 2.7, 5 and $7 \AA$, PVAC has peaks around 2.5 and $5 \AA$ and PVAL has peaks around 1.5 and $2.7 \AA$. The result must approximately agree with the peaks of the radial distribution function of hard sphere. The linear length of CGP of PE, PS, PMMA, PVAC and PVAL evaluated by our theory must be the smallest size of CGP and the blob of melt version, that is, hard spheres having an attractive force. It should be noted that the mean field approximation ${ }^{21}$ almost perfectly holds for the melt of polymers, though the mean field approximation does not hold in a dilute polymer solution.

In Figure 1, we show the plot $c T^{*} v s . M$. This figure shows that $c T^{*}$ seems to have a tendency in direct proportion to $M$, but the plot is somewhat wide. The dispersion of the plots must be related to the chemical structure of the polymers.

$T_{\mathrm{m}}^{*}$ and $T_{\mathrm{LJ}}^{*}$ for monomers(ethylene and propylene) almost agree with each other. Since $T_{\mathrm{m}}^{*}, T_{\mathrm{LJ}}^{*}$ and $T_{\mathrm{r}}^{*}$ have good agreement with each other, the estimation of $T_{\mathrm{r}}$ per repeating unit has great validity. In addition $T_{\mathrm{r}}^{*}$ coincides with $c T^{*}$, the result of our theory per repeating unit. For PE, we use $T_{\mathrm{c}}$ of $\left(-\mathrm{CH}_{2} \mathrm{CH}_{2}-\right)$, and $T_{\mathrm{r}}^{*}$ and $c T^{*}$ are per $\left(-\mathrm{CH}_{2}-\right)$. These results suggest the quantitative validity of our theory.

$c T^{*}$ per repeating unit agrees with $T_{\mathrm{r}}^{*}$ estimated by

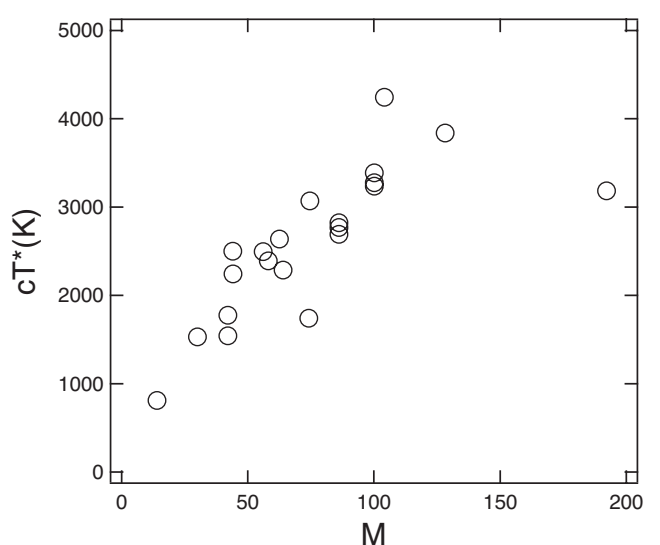

Figure 1. The plot of $c T^{*} v s . M$.

the $T_{\mathrm{c}}$ of the repeating unit. The values of $\mathrm{PE}$ and polypropylene (PP) coincide with the $T_{\mathrm{LJ}}^{*}$ values. Generally, $c T^{*}$ agrees with $T_{\mathrm{r}}^{*}$, but the $c T^{*}$ of a polymer having (-COO-) or $(-\mathrm{COOH})$ groups is somewhat smaller than $T_{\mathrm{r}}^{*}$. In addition, since $c T^{*} / M$ is not constant, we postulate that $c T^{*}$ or $c T^{*} / M$ must depend on the chemical structure and stiffness of a polymer. The conformer model ${ }^{22}$ suggests that $c T^{*} / M$ is constant. Table II shows that $T^{*}$ or $c T^{*}$ of the polymer may have a temperature dependence. The unperturbed dimensions of the polymer in a $\Theta$ solvent have a temperature dependence. ${ }^{23}$ These results suggested that the stiffness of the polymer molecule has a temperature dependence. Therefore, $T^{*}$ or $c T^{*}$ must have a temperature dependence. As concerns $T^{*}$ or $c T^{*}$, we must relate with great precision our theory to the conformer model ${ }^{22}$ and the helical wormlike chain model. ${ }^{24}$ Matsuoka ${ }^{22}$ concluded that molecular weight of one conformer is equal to 9.6 that is smaller than that of repeating unit of PE $\left(-\mathrm{CH}_{2}-\right)$. The validity of our result that $c$ of several polymers are larger than 1 is supported by or agreed with the conformer model by Matsuoka. In the future, we hope that we can evaluate $c T^{*}$ based on the chemical structure of the polymer, just the same as $T_{\mathrm{c}}$ was reviewed by Reid et al. ${ }^{12}$ If we can estimate the $c T^{*}$ based on the chemical structure of the polymer $c T^{*}$ must reflect the change of conformation. The conformation (or stiffness) of polymer must change with temperature and the stiffness of polymer melt is represented by the parameters contained in the helical wormlike chain model. ${ }^{24}$

Acknowledgment. The author would like to acknowledge the continuing guidance and encouragement of Dr. F. Hamada. We would like to thank Professors K. Yamada, H. Miyaji, T. Kanaya and Y. Tsunashima, Dr. Y. Yoshimura of Kyoto University, Japan, and Professor S. Suehiro of Kurashiki City College, Japan for their helpful advice on my work. 


\section{REFERENCES}

1. M. Murakami, J. Chem. Phys., 120, 6751 (2004).

2. a) J. E. Lennard-Jones, F. R. S. and A. F. Devonshire, Proc. R. Soc. London, Ser. A, 163, 53 (1937).

b) J. E. Lennard-Jones, F. R. S. and A. F. Devonshire, Proc. R. Soc. London, Ser. A, 165, 1 (1938).

3. T. L. Hill, "Introduction to Statistical Thermodynamics," Addison-Wesley, Reading, MA, 1962.

4. K. Fujisawa, T. Siomi, F. Hamada, and A. Nakajima, Polym. J., 13, 993 (1981).

5. a) S. Onogi, "Rheology for Chemist," Kagaku Dojin, Kyoto, 1982.

b) A. J. Kovacs, Adv. Polym. Sci., 3, 394 (1964).

6. I. C. Sanchez and R. H. Lacombe, Macromolecules, 11, 1145 (1978).

7. I. Prigogine, "The Molecular Theory of Solutions," NorthHolland, Amsterdam, 1957.

8. P. J. Flory, R. A. Orvoll, and A. Vrij, J. Am. Chem. Soc., 86, 3507 (1964).

9. a) H. Eyring and J. O. Hirschfelder, J. Phys. Chem., 41, 249 (1937).

b) S. Glasstone, K. J. Laidler, and H. Eyring, "The Theory of Rate Processes," McGraw-Hill, New York, N.Y., 1941.

10. D. Patterson, Macromolecules, 2, 672 (1969).

11. D. W. Van Krevelen and P. J. Hoftyzer, "Properties of Polymers," Elsevier, Amsterdam, 1976.

12. R. C. Reid, J. M. Prausnitz, and B. E. Poling, "The Proper- ties of Gases and Liquids," McGraw-Hill, New York, N.Y., 1987.

13. "Handbook of Chemistry," The Chemical Society of Japan, Maruzen, Tokyo, 1993.

14. T. R. McCalla, "Introduction to Numerical Methods and Fortran Programming," John Wiley \& Sons, New York, N.Y., 1967.

15. P. Zoller and D. Walsh, "Standard Pressure-Volume-Temperature Data for Polymers," Technomic Publishing, Lancaster, PA, 1995.

16. A. Quach, P. S. Wilson, and R. Simha, J. Macromol. Sci. Phys., 9, 533 (1974).

17. P. A. Rodgers, J. Appl. Polym. Sci., 48, 1061 (1993).

18. M. Misawa, T. Kanaya, and T. Fukunaga, J. Chem. Phys., 94, 8413 (1991).

19. G. R. Mitchell, B. Rosi-Schwartz, and D. J. Ward, in "Self Order and Form in Polymeric Materials," A. Keller, M. Warner, and A. H. Windle, Ed., Chapman \& Hall, London, U.K., 1995, p 95.

20. A. Bjørnhaug, Ø. Ellefsen, and B. A. Tønnesen, J. Polym. Sci., 12, 621 (1954).

21. P. G. de Gennes, "Scaling Concepts in Polymer Physics," Cornell University Press, Ithaca, N.Y., 1979.

22. S. Matsuoka, "Relaxation Phenomena in Polymers," Hanser, New York, N.Y., 1992.

23. P. J. Flory, "Statistical Mechanics of Chain Molecules," John Wiley \& Sons, New York, N.Y., 1969.

24. H. Yamakawa, "Helical Wormlike Chains in Polymer Solution,” Springer, Berlin, 1997. 